\title{
THE APPLICATION OF INTENTIONAL SUBJECTIVE PROPERTIES AND MEDIATED COMMUNICATION TOOLS TO SOFTWARE AGENTS IN ONLINE DISPUTES RESOLUTION ENVIRONMENTS.
}

\author{
Renzo Gobbin \\ School of Information Sciences and Engineering
}

University of Canberra

\begin{abstract}
This paper examines the use of subjective properties in modeling an architecture for cooperative agents using Agent Communication Language (ACL) that is used as a mediating tool for cooperative communication activities between and within software agents. The role that subjective and objective properties have in explaining and modeling agent internalization and externalization of ACL messages is investigated and related to Vygotsky's developmental learning theories such as Mediated Activity Theory. A novel agent architecture ALMA (Agent Language Mediated Activity) based on the integration of agents' subjective and objective properties within an agent communication activity framework will be presented. The relevance of software agents subjective properties in modeling applications such as e-Law Online Dispute Resolution for e-business contractual arrangements using natural language subject/object relation in their communication patterns will be discussed.
\end{abstract}

\section{INTRODUCTION}

The ability of corporations, businesses and web users to conduct commercial transactions on the Internet is continually growing together with the high number of legal disputes originated by online activities. Following this growth, business web users have found that they need better and newer ways to conduct the equivalent of their traditional business functions under current commercial law. For example if a law firm has had a traditional way of executing dispute resolution, by entering the e-business environment the same law firms will be wondering what the best ways are in utilizing the Internet and associated technologies for business purposes.

Many e-business online contracts are today executed by computer systems employing software agents without any human intervention (Bing \& Sartor 2003). In the area of Law and Online Dispute Resolution the use of intelligent agents requires a fine tuned speech-act or natural language communication and an investigation in the way intelligent agents can internalise and externalize their communications to achieve their purpose. In the legal context intelligent agents will need to use a range of communicative tools to transfer meaningful messages used in a range of cooperative activities. Cooperation, defined as working together to achieve a common aim, i.e. multiple software agents working together, requires agents' communicative capacity in order to exchange information about agents' common goals, their own identity, and their current status (Franklin \& Gaesser 1996, Odell 2000, Klush 2000, Cohen \& Levesque 1995).

While performing cooperative activities with other agents, an agent can send and receive ACL Speech-Act messages (Finin et al 1994, FIPA 2004). Although deprived of the richness of human verbal communication, a substantial form of communication is achieved. We have applied Vygotsky's developmental learning theories (Vygotsky 1978, 1986) on the internalisation and externalisation processes of speech and thought and the use of communication as mediating tool and modeled Vygotsky's theories in a communicative agents' architecture (Gobbin 1998a, b, Jentzsch \& Gobbin 2003).

By using mediated activity theories a cooperative agent architecture could be modeled according to the following characteristics:

- The ability to use natural language, ACL or symbolic patterns as communicative tools mediating agents cooperative activities.

- The ability to use Subjective and Objective properties required by intelligent agents to perform bi-directional multiple communication activities.

- The ability to Internalise representations of perceived communicative patterns from agents or humans. 
- The ability to Externalise internally stored representations of communication patterns to other agents or humans.

The use of language as tool, as suggested in mediated activity theories proposed by Vygotsky (1978, 1986) for the explanation of cognitive development, will provide a proper theoretical framework for investigating multiple cooperative agent communication activities. In particular the aspects of internalisation and externalisation of information, together with related intentional subjective qualities inherent to the communicative processes can provide a useful paradigm for novel software agents communication architectures.

\section{SUBJECTIVE / OBJECTIVE QUALITIES}

The differentiation between Subjective and Objective qualities in entities has been one of the important philosophical investigations since Aristotle and is still actively researched by modern scholars. It is to be noted here that subjective and objective concepts have changed in modern times from the ones used in seventeen century by Descartes and Spinoza. German philosophers Kant and Fitche were the originator of the changes so that these concepts are used in an opposite way than the seventeen century. While the subject is said to be the knowing entity, the object on the contrary is something which, while subjected by the thinking processes of the knowing entity still maintains its own objective nature in independence of the opinions of the knowing entity. In this paper I will apply post-Kant philosophical concepts of Subjectivity and Objectivity into the area of intelligent software agent communication. Intelligent systems, such as communicative software agents, should be able to represent themselves as subjects in an objective world. Work on subjectivity done in modern times philosophy spacing from Kant and Hegel through Peter Strawson, Gareth Evans and recently Paul Ricoeur are important in agent self representation within this context (Ricoeur 1992, Kant 1929, Strawson 1966, Evans 1982, Nagel 1974, Lycan 1990)

In this context an intelligent software agent able to communicative activity and of representing itself as a Subject in an Objective world whose existence is independent of the agent itself should have the following properties:

- Objectivity refers to the view that the truth of a thing is independent from the observing

Subject (in our case an intelligent agent or a person). This notion entail that there are objective entities existing independently from a software agent and that they are external to the agent itself. Objective truths are independent from the software agent's desires, beliefs and intentions. In our investigation the concept of Objectivity is important for the internalization communicative activities and their necessity for software agent inferential internal states.

- Subjectivity on the other end denotes that the truth of some class of externalised statements depends on the internal states or reactions of the software agent making the statement. The notion of Subjectivity is that knowledge is restricted to a software agent own perceptions and the objective qualities experienced by a software agent are subject to its internal interpretations, beliefs, desire and intentions.

\section{LEGAL ASPECTS OF SOFTWARE AGENTS EXTERNALISED SUBJECTIVITY.}

Whenever software agents (SA) execute their agency behaving as intelligent entities we tend to attribute to these artificial entities a behavioural mode similar to humans. If, as an example, an SA enters in communication mode exchanging contracts onLine with the related legal issues involved then we tend to expect a conventional behaviours in this situated environment and also attribute to the SA some kind of mental states.

This attribution seems to clash with the notion that mental states only apply to humans. In this paper we will only examine human and software agents cognitive mental states and behaviour relevant to the Law. An issue emerges at this point: If we have to take into account human mental states and artificial artifacts mental states differently, then we will need to legislate and apply a different or duplicate law for Intelligent software agents (Bing \& Sartor 2003). An alternative to this course of action is the use of Dennett's intentional stance that interpreting mental concepts in a flexible way 
can be applied in legal analysis interaction activities of both humans and intelligent software agents (Bing \& Sartor 2003, Dennett 1997)

In choosing Dennett's intentional stance we assume that behaviour and related belief, desire and intention (BDI) forms of cognitive mental states are directing and motivating an intelligent software agents activity including their epistemic states (Information on object in the world) and their conative states. (Information on what objective goals to achieve)

By applying an intentional stance to the analysis of software agents activities we should:

1 Treat the software agent as a rational agent.

2 Examine the BDI the agent should have. (given his objective place in the environment)

3 Forecast rational normative activities the agent should perform in light of its BDIs.

4 Confirm that the agent is performing his activities in a consistent and rational way.

Whenever in the light of the considerations above, an intelligent software agent appears to possess the capacity to process and communicate knowledge as intentional subjective state then we are justified in attributing to such an agent a number of BDIs and associated mental states (Bing \& Sartor 2003).

Accordingly, the Law should give legal relevance and recognise subjective intentionality in Sofware Agents acting in the online marketplace for their legal owners. Recognition of intelligent software agents systems and mixed systems including humans and agents subjective intentionality would imply:

Interacting software agents above would be authorised to attribute subjective intentional states to hybrid systems they interact with. In this case software agents will appear to have subjective intentional states and/or to exhibit them by speech- act communication.

Interacting software agents will not be able to avoid objective interpretation of the other system behaviour which corresponds to intentional states on the basis of ontological conventions applicable to the communicative interaction at hand.

In an hybrid online ebusiness environment, characterised by human and software agents interactions, the alternative between objectifying Human Computer Interaction (HCI) communicative activities in behavioural terms and subjectifying the same activities by using a BDI intentional stance needs to be considered. Adopting the intentional stance is not an arbitrary choice. Such perspective represents most of the times the only possibility to explain and foresee objective behavioural activity of complex software agents (Bing \& Sartor 2003).

Subjective intentional stance can be useful in putting humans and agents in a equal position in legal relationships and disputes. When collective organisational transactions involving customers, software agents and companies interact together in online communicative fashion then all the collective internal and external interactive members need to be considered as possessing subjective intentional states and BDI. The intentional stance can provide more information for legal enforcement and judgment in case of disputes than the behavioural examination of activities.

Online Dispute Resolution involving software agents and their legal owners (Online Companies) will therefore require a clear identification of who are the legal subjects in the dispute and the examination of relevant intentional motivations behind online behavioural activities.

\section{MEDIATED ACTIVITY THEORY AND SOFTWARE AGENTS}

An important aspect of mediated activity theory is the use of tools as mediators in performing an activity thence the term mediated (Gobbin 1998 a,b, Kaptelinin 1996). A theoretical approach for cooperative multi-agents can make use of communicative tools mediation and the cognitive view of tool mediation that applies the concept of tool mediation to the use of language or signs as mediating factors (Kuuti 1996, Lock \& Peters 1996, Nardi 1996). The dialectic process generated by subjectobject relationship clearly influenced recent theories on thought and language and their developmental processes (Parker 1993, Kuuti 1991). 


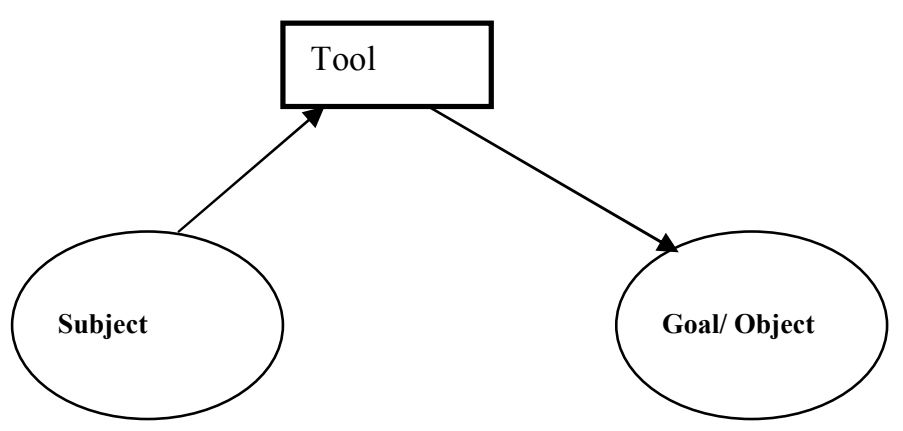

Activity Environment

\section{Figure 1: Tool Mediated Activity Model}

Cognitive scientist and philosophers are often implying, in a metaphorical way, that speech and language are in fact mediating tools used in a communication activity. For example, Wittengstein (1958) in his "Philosophical Investigations" relates tools in a toolbox with word generation functionality while Kempson (1977) contrasts Austin's (1965) concept of speech-act with Grice's (1989) co-operative principle of communication.

Vygotsky's tool mediation theories have been recently proposed using the model described in figure 1 in research on Human Computer Interaction software applications design (Kaptelinin 1992).

The use of language tool mediation in the area of cooperative multi-agents communication is novel but appropriate as an agent identity represents the dialectical difference between external and internal communication activities. Subjective and objective properties acquired during communication can therefore be merged in a single agent entity as illustrated in figure 2 .

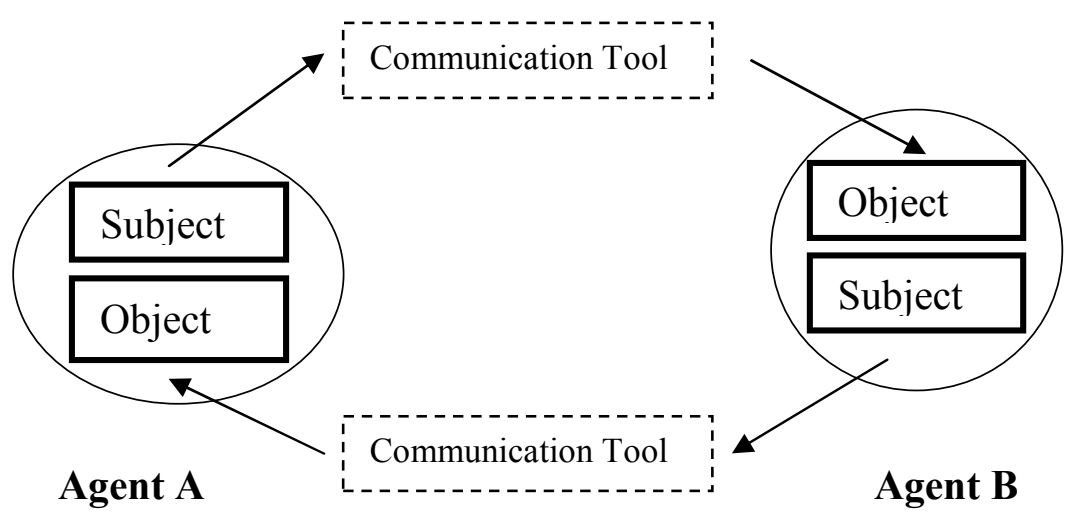

Figure 2. Multi-Agent Communicative Tool Mediated Activity Model 
From a computer science perspective agents are considered autonomous, asynchronous and using distributed processes with their distinct objective related traits. From the AI (Artificial Intelligence) perspective agents are considered communicative, intelligent and rational with the possibility of intentional communication so that they could qualify for subjective traits. These two perspectives require different architecture and modeling approaches. While the first perspective have objective characteristics of software tools the second implies intelligent communication and therefore requires a subjective paradigm. By using a mediated activity model with agents' subjective as well as objective characteristics, an integration of computer science perspectives and AI perspectives can be achieved. The new model for software agents under investigation can describe subjective intentional agent mediated activities and at the same time takes into account the agent objectivity while communicating with other agents.

The agent tool mediated activity model proposed analyses agent subjectivity, its internal and external software tool processes and its objectivity in asymmetric fashion. Mediated Activity models provide a framework for the analysis of agent activities in a historical time frame leading to an understanding of temporal changes in agent's knowledge and behaviour. This type of analysis is broadened to cover pattern of activity rather than episodic staged situations.

The asymmetry between communicative tools and agents provides a comprehensive model for multi-agents where activity frames that can be examined singularly or in an historical succession. The range of agent activities necessarily involves agents' motives that are mainly of environmental origin. While agent actions are always goal driven, agent operations involve formal interaction of the agents' subjectivity with agent objectivity with the mediation of communicative tools. An agent can be a substitute for a range of human activities in a situated commercial or industrial context and mediated activity is an ideal framework for modeling agent activities where agents' individual actions and activities are analysed in a contextual environment. Agents' activities are also dynamic and under continuous development this is especially true in an historical related environment.

The Agent Language Mediated Activity (ALMA) architecture currently being investigated differentiates processes at various categories and levels taking into consideration the objects to which these processes are oriented. Activities are oriented to motives. Each motive is a conceptual object that satisfies an agent need. Actions are the processes functionally and hierarchically subordinated to activities and they are oriented at specific agent own goals. Actions are realised through step-by-step operations that are also determined by the actual condition of activity and its environment.

The ALMA model is also a modeling tool useful in the analysis of cooperative agents team activities supporting the BDI (Belief, Desire, Intention) agent architectures (Busetta et al 1999). Metarepresentations and relevance theories can also be applied to ALMA architectures with agent internal activities designed for cooperative communication concepts (Edmond \& Papazoglou 1998, Wiederhold 1994, Doran et al 1997, Sperber 2000)

\section{EXTERNALISATION AND INTERNALISATION OF SOFTWARE AGENT COMMUNICATION ACTIVITIES}

Often software agents communicative activities are misunderstood as an encoding/decoding process related only to the interpretation of complex linguistic codes. The work of an encoding/decoding device is not certainly inferential or creative. It is not inferential because the symmetrical relation between a message and a signal is quite different from the asymmetric relation of premises to conclusion i.e. the meaning of a sentence doesn't logically follows from its sound. Also an encoding/decoding device is rarely creative. It would be dangerous if it was so. A creative encoding/decoding that will change the process symmetry quite often will generate communication errors. Therefore encoding/decoding can only be just an ancillary process of any creative and inferential language mediated activity (Sperber 1994).

A creative and inferential communication activity will require the asymmetric model provided by the ALMA architecture in order to be able to perform internal communicative activities as well as the external ones. Inferential activities are encapsulated inside an agent architecture involving the 
processing of internalized conceptual representations stored in the agent internal knowledge bases. In the Mediated Activity model described above, communicative subjective expressions are externalised by an agent using mediating linguistic tools. Subsequently the same agent can internalise communicative expressions in an objective fashion. We can see two important activities performed by a communicating agent:

1 Externalisation of agents' internal representations inferences encoded in ACL by using a subjective activity.

2 Internalisation of communicative external ACL representations by using an objective activity.

An agent should be able initially to externalise internally stored ontologies and knowledge bases data ontogenetically implanted by the system designer at agent creation time (Gruber 1993, Guarino et al 1994, Guarino \& Welty 2000). An agent should be able also to dynamically internalise communicative activities into its internal knowledge base. The capability of externalise inferential knowledge previously internalized by agents during the process of communication mediated activities implies the performance of internal inferential activities in the agent architecture. The analysis of these activities are extremely important for modeling agents' adaptation, learning and development processes and will be thoroughly investigated in our next stage of research.

\section{AGENT LANGUAGE MEDIATED ACTIVITY MODEL}

The Agent Language Mediated Activity Model (ALMA) agent architecture currently under research is based on the mediated activity framework described above and is able to describe a range of internal and external communication activities performed by multi-agents.

The ALMA model is designed to perform activities in an environment described in in figure 3 where the communicative process between agents uses an Agent Communication Language and is based on subjective and objective communication interfaces. These interfaces are specifically designed to provide the range of communicative activity capabilities necessary for an agent to perform the externalization of internally produced ACL messages and the internalization of ACL messages received from the environment. Subjective and Objective inference engines are inbuilt inside the agent model because the subjective and objective properties are created internally by the inferential and conceptualization process. ALMA will use also a number of specialized knowledge bases tailored for the each of the specific subject and object modules. A knowledge base for high level meta-representations will provide also an integrated KBS environment using specialized ontologies. A multiple ontology environment capable to store communicative representations for both internalization and externalization activities will be available together with an ontology for conceptual meta-representation.

The ALMA model could also be associated with recent cognitive sciences theories such as language meta-representations and relevance together with theories of social cooperation. ALMA internal modules will be developed taking into account the current standardization efforts by a number of multi-agents research organisations. The ALMA architecture will evolve as the research continues in the area of meta-representations, conceptual representation and relevance modules (Castelfranchi \& Werner 1994, Keil 1979, Sperber \& Wilson 1995, Chomsky 1975, 1980). 


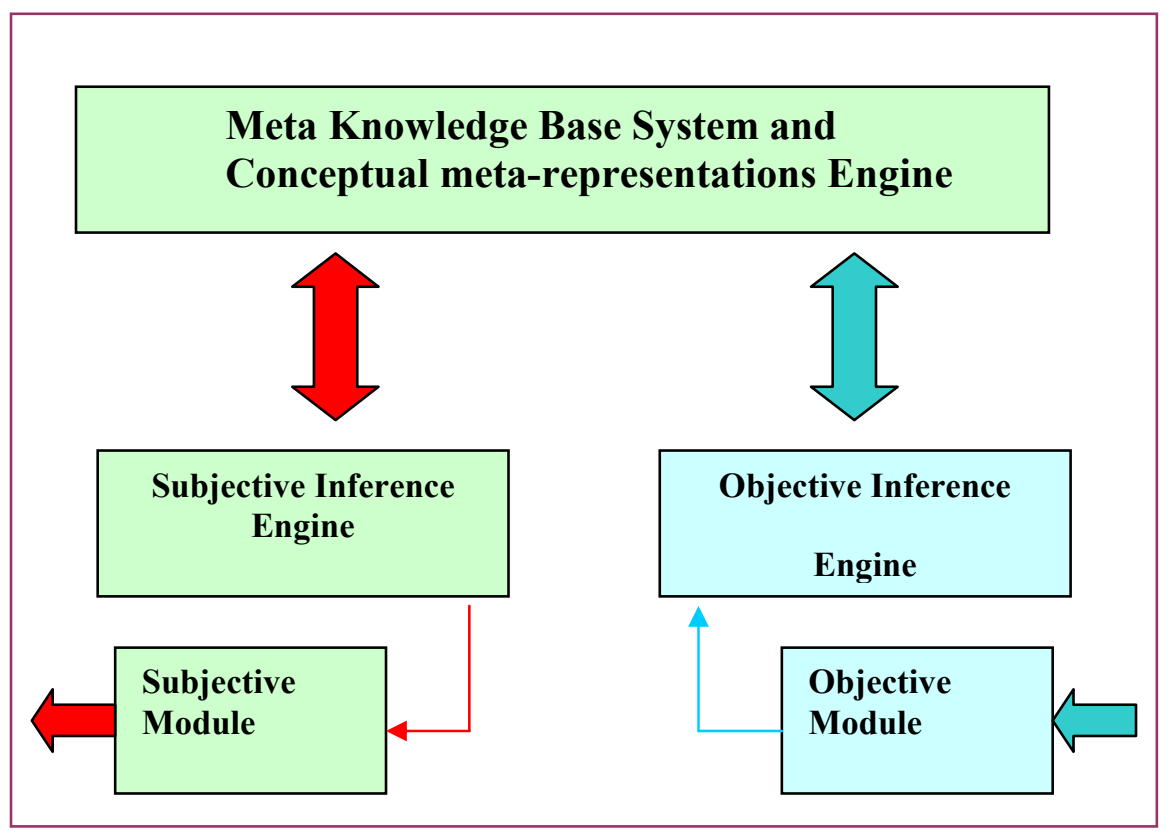

Figure 3. ALMA Architecture

\section{CONCLUSION}

The application of Mediated Activity Theory in the area of Human Computer Interaction (HCI) analysis. can be extended to the analysis and construction of cooperative agents' architectures performing communicative and learning activities.

This extension is generating a number of interesting Artificial Intelligence (AI) considerations that are quite different from mediated activity applications in the HCI field. Internalisation and externalisation together with subjectivity and objectivity aspects of cooperative agents tool mediated activity requires a multi-disciplinary approach quite consistent with Intelligent Systems and multiagent technology.

The dialectical relations between internalisation and externalisation together with agent subjectivity and objectivity can provide new paradigms for agent internal processes such as self-identification, $\mathrm{KB}$ storage of internalized concepts and externalization of inferred concepts from the internal knowledge base. We are currently investigating the implementation of the ALMA architecture under research in legal applications such as Online Dispute Resolutions where the human/agent natural language interaction and semantic communication is used more frequently.

The subjective intentional paradigm inbuilt in the ALMA model can integrate hybrid systems where human customers and software agents communicative activities are performed thus providing equal subjective and intentional position for legal assessment and resolution of online disputes.

\section{REFERENCES}

Austin, J.L. (1965) How To Do Things With Words. Oxford University Press, New York. Bing, J. and Sartor, G. (2003). The Law of Electronic Agents, 76-114. Unipunskriftserier. Oslo. Busetta, P., Hodgson, A. and Ronnquist, R. (1999). Specification of Coordinated Agent Behaviour.

IJCAI'99 Workshop on Team Behavior and Plan Recognition. pp 75-81.

Castelfranchi, C. and E. Werner, (1994). Artificial Social Systems, LNAI, Springer.

Chomsky, N., (1975). Reflections of Language. Random House, New York.

Chomsky, N., (1980). Rules and Representations. Columbia University Press, New York. 
Cohen, P.R. and H.J. Levesque, (1995). Communicative Actions for Artificial Agents. Proceedings of the First International Conference on Multi-Agent Systems, AAAI Press, San Francisco, June 1995.

Damasio, A.R., (2003). Looking for Spinoza. William Einemann, London.

Dennett, D. C., (1997). Kinds of Minds: Towards an Understanding of Consciousness. Basic Books, New York, US

Doran J.E., S. Franklin, N.R. Jennings, and Norman T.J., (1997). On Cooperation in Multi-Agents Systems. The Knowledge Engineering Review, Vol. 12(3).

Edmond, D. and Papazoglou, M.P., (1998). Reflection is the essence of cooperation. M.P. Papazoglou and G. Schlaegeter (Eds.), Cooperative Information systems: Trends and Directions, Academic Press, pp.233-262.

Evans, G., (1982). Varieties of Reference. Ed. J. McDowell. Oxford University Press, UK.

Finin, T., D. McKay, R. Fritzson, and R. McEntire, (1994). KCaML, Information and Knowledge Exchange Protocol. K. Fuchi and T. Yokoi (Ed.), Knowledge Building and Knowledge Sharing, Ohmsha and IOS Press, 1994. http://www.csee.umbc.edu/pub/ARPA/kqrrd/papers/

FIPA, Agent Communication Language. http://www.fipa.org/spee/fipa97/FIP.k97.html. last accessed 02 March 2004.

Franklin, S. and Gaesser, A., (1996). "It is an Agent or just a program? Taxonomy for autonomous agents." Proc. 3rd International Workshop on Agent Theories, Architectures and Languages (ATAL-96), Springer, LNAI.

Gobbin, R., (1998). Adoption or Rejection: Information systems and their cultural fitness. Information Systems and Activity Theory: Tools in Context. H. Hasan, E. Gould and P. Hyland (Eds.) Wollongong University Press.

Gobbin, R., (1998). The role of cultural fitness in user resistance to information technology tools. Interacting with Computers, 9, 275-285. Elsevier Science UK.

Grice, P., (1989). Studies in the Way of Words, Cambridge, Mass.: Harvard University Press.

Gruber, T.R., (1993). A translation approach to portable ontology specifications. Knowledge Acquisition, 5:pp199-220.

Guarino, N. and Welty, C., (2000). Ontological Analysis of Taxonomic Relationships. Laender,A and Storey, V., eds., Proocedings of ER-2000: The International Conference on Conceptual Modeling. October. Springer-Verlag LNCS.

Guarino, N., Carrara, M., Giaretta, P., (1994). An Ontology of Meta-level Categories. Journal of Knowledge Representation and Reasoning: Proceedings of the Fourth International conference (KR94), Morgan Kaufmann, San Mateo, California. J. Mariga ed., IRM Press, US.

Jentzsch, R. and Gobbin, R., (2003). A Cooperative Communicative Intelligent Agent Model for ECommerce. Managing E-commerce and Mobile Computing Technologies.

Kant, Immanuel. Critique of Pure Reason, trans. Norman Kemp Smith., 1929 edition, St.Martin's Press, New York.

Kaptelinin, V., (1992). Human Computer Interaction in Context: The Activity Theory perspective. In Proceedings, East-West Human Computer Interaction Conference, St Petersburg.

Kaptelinin, V., (1996). Computer Mediated Activity. Context and Consciousness, Nardi, B. ed., MIT Press, Cambridge.

Keil, F., (1979). Semantic and Conceptual Development: An Ontological Perspective. Cambridge, MA: Harvard University Press.

Kempson, R.M. (1977). Semantic Theory. Cambridge University Press, UK.

Klush, M., (2000). Intelligent information agents: Agent based information discovery and management on the Internet, Springer Verlag.

Kuutti, K., (1991). Activity Theory and its applications to information systems. H. E., Nissen ed., Information Systems Research, Amsterdam, Elsevier Science Publisher.

Kuutti, K., (1996). Activity Theory as a potential framework for HCI research. Context and Consciousness, Nardi, B., ed., MIT Press, Cambridge.

Lock, A.J. and Peters, C.R., (1996). Social Relations, Communication and Cognition. Handbook of Human Symbolic Evolution. Eds Lock A.J. and Peters C.R., Clarendon Press, Oxford. 
Lycan, W., (1990). Mind and Cognition. Blackwell, Oxford.

Nagel, T., (1974)."What Is It Like to be a Bat?" Philosophical Review n.83 (1974), pp.435-50

Nardi, B.A., (1996). Studying Context. Context and Consciousness. Nardi, B., ed.,MIT Press, Cambridge.

Odell, J. Ed., (2000). Agent Technology, OMG Document 00-09-01, OMG Agents interest Group, September 2000.

Parker, S.T. (1993) Higher intelligence, propositional language and culture as adaptation for planning. Tools, Language and Cognition in Human Evolution. Eds Gibson,K. and Ingold, T. Cambridge University Press, UK.

Ricoeur, P., (1992). Yourself as Another. University of Chicago Press, USA

Sperber, D. and Wilson, D., (1995). Relevance: Communication and Cognition, Blackwell. Oxford.

Sperber, D., (1994). Understanding Verbal Understanding in What is Intelligence? J. Khalfa ed., Cambridge University Press.

Sperber, D., (2000). Metarepresentations in an evolutionary perspective. In Dan Sperber Representations: A Multidisciplinary perspective. Oxford University Press.

Spinoza, B., Ethics. Trans. W.A. White\& A.H. Sterling, 2001 edition, Wordsworth, UK,

Strawson, Peter F., (1966). The Bounds of Sense: An Essay on Kant's Critique of Pure Reason. Methuen, London.

Vygotsky, L.S., (1978). Minds in Society. Harvard University Press, Cambridge.

Vygotsky, L.S., (1986). .Thought and Language. MIT Press, Cambridge.

Wiederhold, G., (1994). Interoperation, mediation and ontologies. Proceedings of International Workshop on Heterogeneous Cooperative Knowledge Bases, Tokyo.

Wittgenstein, L. (1958). The Blue and Brown Book. Harper and Row. New York. 